\title{
First report of cucumber mosaic virus infecting Morinda officinalis in China
}

\author{
Chong Feng ${ }^{1} \cdot$ Ti-Jiang Shan $^{3} \cdot$ Li Yang $^{1} \cdot$ Miao-Miao Cai ${ }^{1} \cdot$ De-Po Yang $^{2} \cdot$ Zhi-Min Zhao $^{2} \cdot$ Ping Ding $^{1}$
}

Received: 31 January 2020 / Accepted: 24 June 2020 / Published online: 4 November 2020

(C) Società Italiana di Patologia Vegetale (S.I.Pa.V.) 2020

Keywords Morinda officinalis $\cdot$ Cucumber mosaic virus $\cdot$ High-throughput sequencing $\cdot$ RT-PCR

Morinda officinalis How (M. officinalis), an emerging medicinal plant, has gained popularity all over China. During a survey in 2019, we collected 10 M. officinalis plants at each of 5 different sites where $30 \%$ of the plants exhibited viruslike symptoms including foliar mosaic and deformation, and plant stunting in Deqin County, Guangdong Province, China. Total RNA was extracted from symptomatic leaves for high throughput sequencing by Illumina Hiseq 4000 (Illumina, USA) to identify pathogens associated with diseased plants (Kwon et al. 2018; Wang et al. 2018). Sequence analyses revealed three long contigs which covered almost the fulllength genome sequence of cucumber mosaic virus from the genus Cucumovirus in the family Bromoviridae. No other virus was detected. The sequence of contigs was affirmed by de novo sequencing. RNA1, RNA2 and RNA3 of CMV isolate from M. officinalis (CMV-MO) are $3473 \mathrm{nt}$ (GenBank accession No. MT371431), 3078 nt (MT371432) and 2255 nt (MT371433) long, respectively.

RT-PCR was conducted to confirm CMV in M. officinalis plants, by using three primers (CMVMO1_F_5'-ATTCACTT CTCCACGGGTCG-3' and CMVMO1_R_5'-TCAACCAG AACCCTACTAACA-3'; CMVMO2_F_5'-TTGAACCA CCGCCTATCTGT-3' and CMVMO2_R_5'-GCCACAGC CTTACTCAACCT-3'; CMVMO3_F_5'-TAACCCAC GGTCGTATTGCT-3' and CMVMO3_- R_5'-CTAATACG CAACGAAATCACT-3') designed according to the CMV-
MO sequences, respectively. Fragments of 413, 574 and 672 bp were separately obtained for RNA1, RNA2 and RNA3 respectively, and sequenced. BLASTn analysis revealed that the $413 \mathrm{bp}$ fragment shared $96.2 \%$ nucleotide identity with CMV isolate JC from Korea (MH594044), the 574 bp fragment shared $96.9 \%$ nucleotide identity with CMV isolate 20 from Taiwan (MH798143), and the $672 \mathrm{bp}$ fragment shared $94.2 \%$ nucleotide identity with CMV isolate yang-ss3-2 from China (MK778782). CMV was also identified in additional samples of $M$. officinalis plants with mosaiclike symptoms in other fields in the same county. This is the first report of CMV and of any virus in M. officinalis.

Acknowledgements This work was supported by National Key R\&D Program of China (2017YFC1701104).

\section{References}

Kwon S-J, Cho I-S, Yoon J-Y et al (2018) First report of cucumber mosaic virus in Atractylodes macrocephala in Korea. Plant Dis 103(2):380

Wang R, Li Y, Dong J-L et al (2018) First report of tomato yellow leaf curl virus and cucumber mosaic virus infecting Huoxiang (Agastache rugosa) in China. J Plant Pathol 100(3):581

Publisher's note Springer Nature remains neutral with regard to jurisdictional claims in published maps and institutional affiliations.
Ping Ding

dingpinggz@126.com

1 School of Pharmaceutical Sciences, Guangzhou University of Chinese Medicine, Guangzhou 510006, China

2 School of Pharmaceutical Sciences, Sun Yat-sen University, Guangzhou 510006, China

3 College of Forestry and Landscape Architecture, South China Agricultural University, Guangzhou 510006, China 